\title{
Synthesis of water-soluble dye-cored poly(amidoamine) dendrimers for long-term live cell imaging
}

\author{
Yang Cai, Chendong Ji, Shaobo Zhang, Zhiqiang Su* and Meizhen Yin ${ }^{*}$
}

\begin{abstract}
Hydrophilic dendrimers, especially poly(amidoamine) (PAMAM) dendrimers are widely applied in modifying fluorescent dyes to endow them with water solubility and biocompatibility for biologic fluorescence imaging. Common preparation strategies of fluorescent dendrimers including encapsulating dyes or attaching dyes at periphery of dendrimers might cause uncertain constituent and lower biocompatibility. Here, we have developed a series of watersoluble fluorescent dendrimers with dye as core and fanshaped PAMAM as arms. Carboxylated perylene bisimides (PBI) dye and squarylium indocyanine (SICy) dye were conjugated with PAMAM dendrons by amidation to obtain a series of fluorescent dendrimers with enhanced water-solubility. Two PBI based dendrimers (PBI-G2.5 and PBI-G1.5) were chosen as model compounds for further optical, selfassembly and biological studies. In aqueous environment, PBI-G2.5 exhibited strong fluorescence, small size $(\sim 30 \mathrm{~nm})$ and slightly positive surface charge $(\sim 2.46 \mathrm{mV})$, which are ideal for biomedical applications. In vitro assays demonstrated that PBI-G2.5 nanoparticles accumulated in the cytoplasm of HeLa cells with rapid cellular uptake. The strong fluorescence in HeLa cells remained for over $48 \mathrm{~h}$. To conclude, our study provides an effective strategy for preparing water-soluble fluorescent dendrimers towards long-term live cell imaging.
\end{abstract}

Keywords: fluorescent dendrimers, fan-shaped PAMAM, perylene bisimides, water solubility, live cell imaging

\section{INTRODUCTION}

In the past decades, a variety of organic fluorescent dyes have been developed for fluorescence imaging and de- tection [1-4]. However, poor water solubility of organic fluorophores impeded their applications in biological fields [5]. Among all the modification strategies to increase their water solubility, introducing water-soluble blocks, for example, dendrimers, to fluorescent dyes has been proved very effective [6]. Dendrimer is a kind of monodispersed, highly branched synthetic polymers with precisely controllable architecture and composition. It has multilevel interior-surface architecture with different generations [7]. Owing to these advantages, fluorescent dendrimers have been widely used in various areas, such as optical sensors [8,9], drug delivery [10-16], gene delivery [17-21] and imaging contrast agents [22,23]. Especially, poly(amidoamine) (PAMAM) dendrimer with facile synthesis, good water solubility and biocompatibility attracted increasing attention in modifying fluorescence dyes to endow these fluorophores with water solubility and biocompatibility for biologic applications [24].

In general, there are two strategies to modify fluorescent dyes with PAMAM dendrimers. PAMAM dendrimer was used to encapsulate fluorescent dyes into its hydrophobic interior through intermolecular interactions [25] or couple with fluorescent dyes via covalent bond at the periphery of its dendritic scaffolds $[8,26]$. However, these methods usually resulted in uncertain architectures [27] and unpredictable influence on their size, mobility and biocompatibility [28]. Besides, the exposed hydrophobic fluorophores would aggregate in aqueous environment, leading to quenching [29]. Dyes-cored fluorescent dendrimers have been propsed to solve these

State Key Laboratory of Chemical Resource Engineering, Beijing Laboratory of Biomedical Materials, Beijing University of Chemical Technology, Beijing 100029, China

*Corresponding authors (emails: yinmz@mail.buct.edu.cn (Yin M); suzq@mail.buct.edu.cn (Su Z)) 


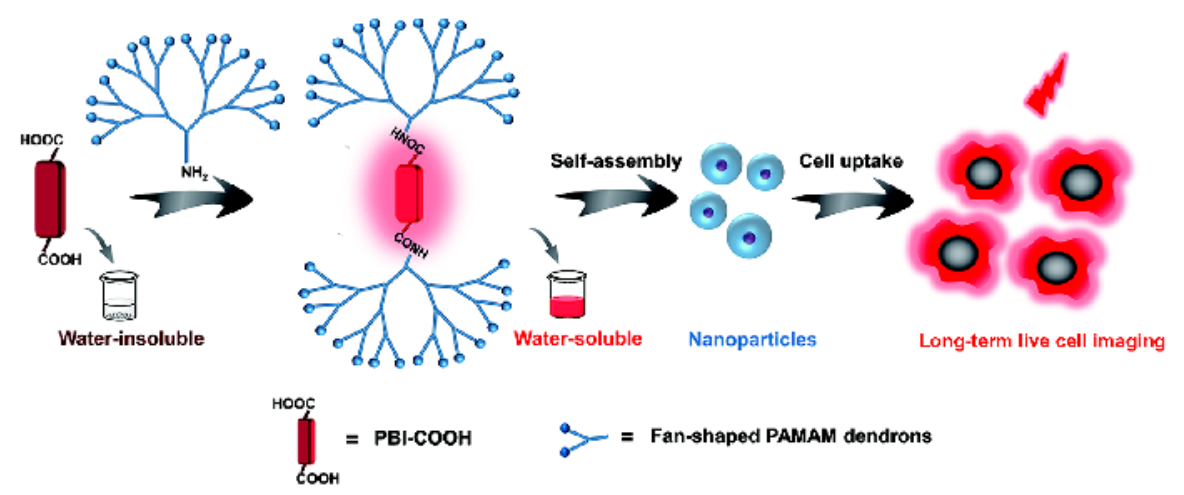

Scheme 1 Schematic illustration of the synthesis, self-assembly and live cell imaging of fluorescent dendrimers.

problems [6]. Instead of synthesizing dye-cored dendrimer via divergent approach, directly attaching dendrimers to fluorescent dye may simplify the preparation process [30]. Fan-shaped PAMAM dendron, as a kind of special PAMAM dendrimer, could be modified at the periphery and the focal point of dendron [24,31]. The fan-shaped PAMAM dendrons are ideal for constructing novel dye-cored dendrimers with enhanced performance.

With the development of biomedical science, fluorescent probes with long-term labeling and dynamic tracking of cells or organelles are urgently needed [32]. The fluorescent dyes with good water solubility, biocompatibility, high photostability and multi-functionality are key but difficult to cell imaging [33-35]. Recently, perylene bisimides (PBI) and squarylium indocyanine (SICy) dyes with high photostability and intense long wavelength emission were used for long-term biolabeling [36-41]. To further improve the water solubility, biocompatibility and functionality of the fluorescent dyes, coupling with fan-shaped solubilizing PAMAM dendrons provided a simple and effective option.

Herein, we presented the synthesis of dye-cored fluorescent dendrimers with fan-shaped PAMAM dendrons for live cell imaging (Scheme 1). PBI or SICy core dendrimers of different generations were obtained with relative high yields. With increasing generation, the PBI dendrimers (PBI-G1.5 and PBI-G2.5) exhibited enhanced water solubility, fluorescence performance and cytocompatibility. As expected, PBI dendrimers had rapid cellular uptake, strong fluorescence and long-term retention time in HeLa cell line. Our study combined both advantages of PAMAM and fluorescent dyes and provided an effective strategy for preparing fluorescent dendrimers with good water solubility and cytocompatibility for long-term live cell imaging, showing great potential in developing novel multi-functional theranostic platforms.

\section{EXPERIMENTAL SECTION}

\section{Materials and methods}

Unless otherwise stated, solvents and reagents were purchased from commercial sources and used without further purification. Ethylenediamine (EDA), di-tert-butyl dicarbonate, perylene tetracarboxylic acid bianhydride (PBA), L-alanine, 1-(3-dimethylaminopropyl)-3-ethylcarbodiimide hydrochloride (EDCI), 1-hydroxybenzotriazole (HOBt), $\mathrm{N}, \mathrm{N}$-diisopropylethylamine (DIEA), etc. were purchased from Heowns, Tianjin, China. Proton nuclear magnetic resonance ( $\left({ }^{1} \mathrm{H}\right.$ NMR) spectra were observed on a Bruker 400 spectrometer at room temperature. Matrix-assisted laser-desorption ionization time-offlight mass spectrometry (MALDI-TOF MS) were determined on AXIMA-CFR plus MALDITOF mass spectrometer. UV-visible spectra were obtained with a spectrophotometer (UV-2600, UV-SPECTROPHOTOMETER, SHIMADZU, Japan) and fluorescence (FL) spectra were acquired on fluorescent spectrofluorimeter (Horiba Jobin Yvon FluoroMax-4 NIR, NJ, USA) respectively. The morphologies of PBI dendrimers were observed with field emission scanning electron microscopy (FESEM, JSM-7500F, JEOL, Japan) manipulated at an accelerating voltage of $10 \mathrm{kV}$. Samples $\left(1 \times 10^{-5} \mathrm{~mol} \mathrm{~L}^{-1}, \quad T=298.15 \mathrm{~K}\right)$ were vacuum sputtered with $\mathrm{Au}$ to increase the contrast before SEM observation. Dynamic light scattering (DLS) and zeta potential of samples were obtained by Malvern Zetasizer Nano instrument with compatible disposable capillary cell (DTS 1070 from Malvern).

\section{Synthesis of fluorescent PAMAM dendrimers}

(1) Synthesis of fan-shaped PAMAM dendrons $\left(\mathrm{NH}_{2}-\mathrm{G}_{n}\right.$, 

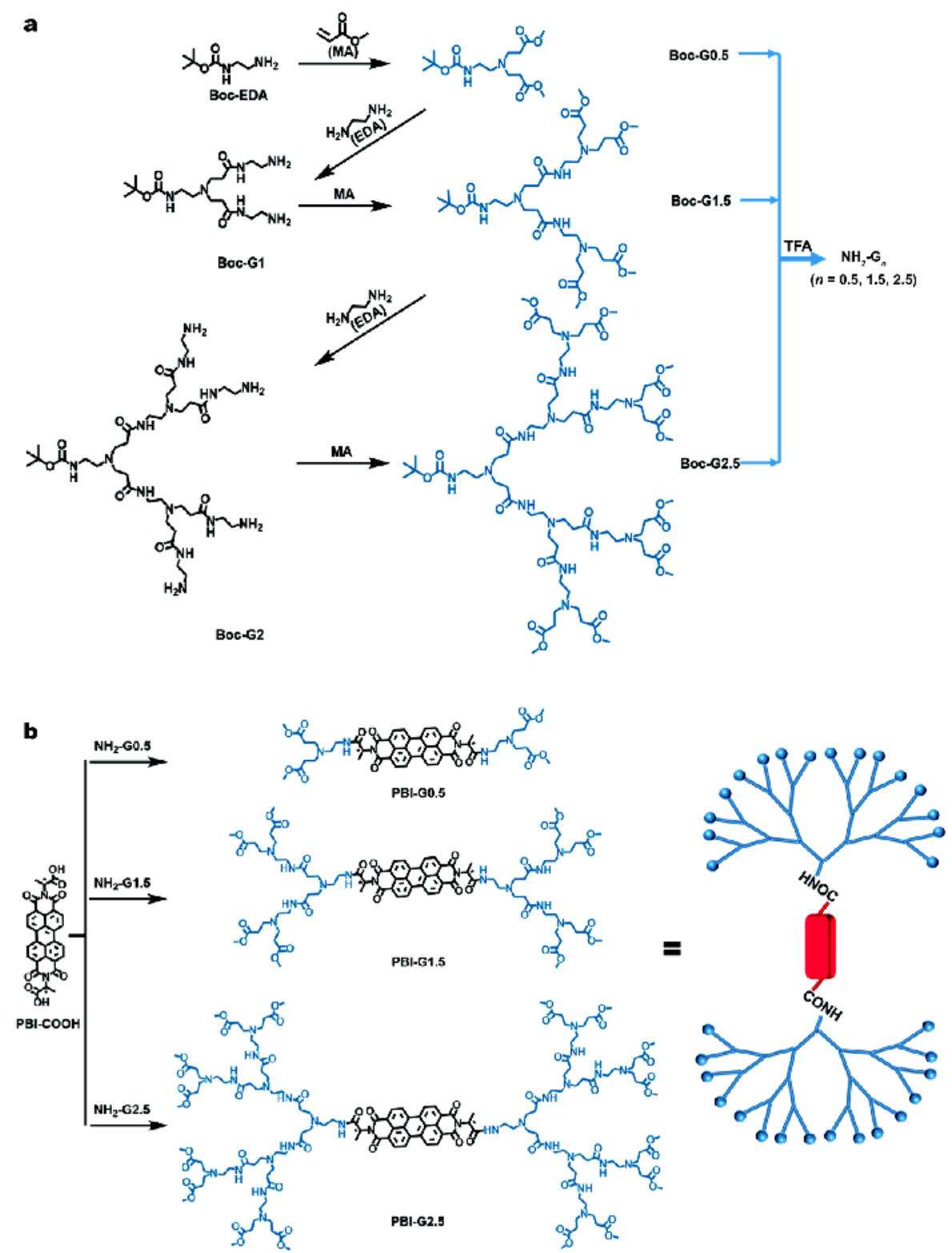

Scheme 2 Synthesis route of (a) fan-shaped PAMAM dendrons and (b) fluorescent dendrimers (PBI-G0.5, PBI-G1.5, PBI-G2.5).

$n=0.5,1.5,2.5)$ (Scheme 2a) $[31,41]$

A. A solution of di-tert-butyl dicarbonate protected ethylenediamine (Boc-EDA) (1 g, $6.24 \mathrm{mmol})$ in methanol was added slowly to a stirring solution of methylacrylate (MA) (5.65 mL, $32 \mathrm{mmol}, 5$ equiv.) in methanol $(10 \mathrm{~mL})$ under nitrogen in an ice bath at $0^{\circ} \mathrm{C}$. After that the mixture was heated to room temperature and further stirred for $24 \mathrm{~h}$. The solvent was removed under reduced pressure and dried under vacuum to gain the product Boc-G0.5 (1.97 g, 95\%) as a pale-yellow oil.

B. A solution of Boc-G0.5 (1.66 g, $5 \mathrm{mmol})$ in methanol
(4 mL) was added dropwise to a stirred solution of EDA $(7.5 \mathrm{~g}, 8.5 \mathrm{~mL})$ in methanol $(10 \mathrm{~mL})$ under nitrogen in an ice bath at $0^{\circ} \mathrm{C}$. After that the mixture was allowed to warm to room temperature and further stirred for $72 \mathrm{~h}$. The solvent was removed under reduced pressure under $40^{\circ} \mathrm{C}$ and dried at $40^{\circ} \mathrm{C}$ under vacuum to gain the product Boc-G1 (1.79 g, 92\%) as a pale-yellow oil.

Successively adding MA and EDA similarly with (A) and (B), we got the desired products Boc-G1.5, Boc-G2.5.

Boc-G0.5. ${ }^{1} \mathrm{H}$ NMR $\left(400 \mathrm{MHz}, \mathrm{CDCl}_{3} \delta\right.$, ppm) 5.02 (s, $1 \mathrm{H}), 3.38(\mathrm{~s}, 6 \mathrm{H}), 2.87(\mathrm{~d}, J=5.4 \mathrm{~Hz}, 2 \mathrm{H}), 2.46(\mathrm{t}, J=6.7 \mathrm{~Hz}$, 
$4 \mathrm{H}), 2.24(\mathrm{t}, J=5.8 \mathrm{~Hz}, 2 \mathrm{H}), 2.14(\mathrm{t}, J=6.6 \mathrm{~Hz}, 4 \mathrm{H}), 1.14(\mathrm{~s}$, $9 \mathrm{H})$.

Boc-G1.5. ${ }^{1} \mathrm{H}$ NMR $\left(400 \mathrm{MHz}, \mathrm{CDCl}_{3} \delta, \mathrm{ppm}\right) 6.97$ (s, $2 \mathrm{H}), 5.44(\mathrm{~s}, 1 \mathrm{H}), 3.65(\mathrm{~s}, 12 \mathrm{H}), 3.24(\mathrm{t}, J=24.9 \mathrm{~Hz}, 6 \mathrm{H})$, $2.73(\mathrm{t}, J=6.6 \mathrm{~Hz}, 12 \mathrm{H}), 2.60-2.19(\mathrm{~m}, 18 \mathrm{H}), 1.40(\mathrm{~s}, 9 \mathrm{H})$.

Boc-G2.5. ${ }^{1} \mathrm{H}$ NMR $\left(400 \mathrm{MHz}, \mathrm{CDCl}_{3} \delta, \mathrm{ppm}\right) 7.67$ (s, $2 \mathrm{H}), 7.01(\mathrm{~s}, 4 \mathrm{H}), 3.67(\mathrm{~s}, 24 \mathrm{H}), 3.28(\mathrm{~d}, J=5.4 \mathrm{~Hz}, 12 \mathrm{H})$, $2.75(\mathrm{t}, J=6.5 \mathrm{~Hz}, 28 \mathrm{H}), 2.54(\mathrm{~s}, 14 \mathrm{H}), 2.43(\mathrm{t}, J=6.5 \mathrm{~Hz}$, $28 \mathrm{H}), 1.42(\mathrm{~s}, 9 \mathrm{H})$.

C. Trifluoroacetic acid (TFA) was added into the vigorously stirring solution of N-protected Boc-Gn in DCM. After stirring for $2 \mathrm{~h}$, the solvent was removed under reduced pressure and dried under vacuum. The crude products were used without further purification.

(2) Synthesis of PBI-G $G_{n}(n=0.5,1.5,2.5)$ (Scheme 2b)

In a typical experiment, PBI with carboxyl groups (PBI$\mathrm{COOH}$ ) (1 equiv.), EDCI (3 equiv.), HOBt (0.8 equiv.) were dissolved in dimethyl sulfoxide (DMF) in a Schlenk flask and the mixture was stirred under $\mathrm{N}_{2}$ at $0^{\circ} \mathrm{C}$ to activate carboxyl (monitored by thin-layer chromatography, TLC). Then DIEA and $\mathrm{NH}_{2}-\mathrm{G}_{n}(n=0.5,1.5,2.5)$ (2.5 equiv.) were added into the mixture after activating and stirred for $8 \mathrm{~h}$ at $0^{\circ} \mathrm{C}$. The mixture was allowed to warm to room temperature and reacted for another $48 \mathrm{~h}$. In the end, the mixture was precipitated in diethyl ether to remove DMF, repeated precipitating three times to produce crude products.

PBI-G0.5. PBI-COOH (100 mg, $0.187 \mathrm{mmol})$, EDCI (108 mg, 3 equiv.), HOBt ( $21 \mathrm{mg}, 0.8$ equiv.), DIEA $(70 \mu \mathrm{L}), \mathrm{G} 0.5$ (2.2 equiv.). The crude product was purified by column chromatography on silica gel with methylene chloride:ethanol (100:0.5, $v / v)$ as an eluent to afford PBIG0.5 (117 mg, 65\%). ${ }^{1} \mathrm{H}$ NMR (400 MHz, $\left.\mathrm{CDCl}_{3} \delta, \mathrm{ppm}\right)$ $8.54(\mathrm{~d}, J=36.1 \mathrm{~Hz}, 8 \mathrm{H}), 5.77(\mathrm{~d}, J=6.9 \mathrm{~Hz}, 2 \mathrm{H}), 3.57(\mathrm{~d}, J=$ $35.6 \mathrm{~Hz}, 16 \mathrm{H}), 2.65$ (d, J=129.7 Hz, 20H), 1.79 (s, 6H). MS (MALDI-TOF, $m / z) m / z 963.3265[\mathrm{M}+\mathrm{H}]^{+} ; 985.3117$ [M $+\mathrm{Na}]^{+} ; 1,001.2893 \quad[\mathrm{M}+\mathrm{K}]^{+} \quad$ (calcd. for $\mathrm{C}_{50} \mathrm{H}_{54} \mathrm{~N}_{6} \mathrm{O}_{14}$ 962.3698).

PBI-G1.5. PBI-COOH (50 mg, $0.093 \mathrm{mmol})$, EDCI (54 mg, 3 equiv.), HOBt (11 mg, 0.8 equiv.), DIEA $(35 \mu \mathrm{L}), \mathrm{G} 1.5-\mathrm{NH}_{2}(130 \mathrm{mg}, 2.2$ equiv.). The crude product was purified by column chromatography on gel permeation chromatography (GPC), dialysed with MWCO 1000, yield $71 \mathrm{mg}, 43 \% .{ }^{1} \mathrm{H}$ NMR $(400 \mathrm{MHz}$, DMSO $\delta, \mathrm{ppm}) 8.79(\mathrm{dd}, J=153.3,7.8 \mathrm{~Hz}, 8 \mathrm{H}), 8.17(\mathrm{~d}, J=$ $27.7 \mathrm{~Hz}, 4 \mathrm{H}), 7.99$ (s, $2 \mathrm{H}), 5.57$ (d, J=7.3 Hz, 2H), 3.59 (s, $24 \mathrm{H}), 3.37(\mathrm{~s}, 20 \mathrm{H}), 3.14(\mathrm{~s}, 12 \mathrm{H}), 2.84(\mathrm{dd}, J=100.5$, $37.0 \mathrm{~Hz}, 36 \mathrm{H}$ ), 1.58 (s, 6H). MS (MALDI-TOF, $\mathrm{m} / \mathrm{z}) \mathrm{m} / \mathrm{z}$ 1,763.9775 $[\mathrm{M}+\mathrm{H}]^{+}$(calcd. for $\mathrm{C}_{86} \mathrm{H}_{118} \mathrm{~N}_{14} \mathrm{O}_{26}$ 1,763.8420).

PBI-G2.5. PBI-COOH (50 mg, $0.093 \mathrm{mmol})$, EDCI
(54 mg, 3 equiv.), HOBt (11 mg, 0.8 equiv.), DIEA $(35 \mu \mathrm{L}), \mathrm{G} 2.5-\mathrm{NH}_{2}$ (295 mg, 2.2 equiv.). The crude product was purified by column chromatography on GPC, dialysed with MWCO 2500, yield $80 \mathrm{mg}, 26 \% .{ }^{1} \mathrm{H}$ NMR $\left(400 \mathrm{MHz}, \mathrm{CDCl}_{3} \delta, \mathrm{ppm}\right) 8.65(\mathrm{~s}, 4 \mathrm{H}), 8.49-7.39(\mathrm{~m}$, $12 \mathrm{H}), 7.08(\mathrm{~s}, 6 \mathrm{H}), 5.73(\mathrm{~s}, 3 \mathrm{H}), 3.65(\mathrm{~s}, 48 \mathrm{H}), 3.59-2.09$ $(\mathrm{m}, 160 \mathrm{H}), 1.78(\mathrm{~s}, 6 \mathrm{H})$. MS (MALDI-TOF, $\mathrm{m} / \mathrm{z}) \mathrm{m} / \mathrm{z}$ $3387.6187[\mathrm{M}+\mathrm{Na}]^{+} ; 3404.3087 \quad[\mathrm{M}+\mathrm{K}]^{+}$(calcd. for $\mathrm{C}_{158} \mathrm{H}_{246} \mathrm{~N}_{30} \mathrm{O}_{50}$ 3363.7629).

The synthetic routes and characterizations of di-tertbutyl dicarbonate protected ethylenediamine (Boc-EDA), PBI-COOH and SICy dendrimers can be found in Fig. S1, S2.

\section{RESULTS AND DISCUSSION}

The synthetic route of fluorescent dendrimers is shown in Scheme 2. The synthetic route includes the synthesis of fan-shaped PAMAM dendrons and conjugation of dendrons to carboxyl group bearing fluorophores. Firstly, the fan-shaped PAMAM dendrons were synthesized by divergent method from di-tert-butyl dicarbonate protected ethylenediamine (Boc-EDA) (Scheme 2a) [31]. The remaining unprotected amine of Boc-EDA reacted with methylacrylate (MA) through Michael reaction to yield Boc-G0.5. Then Boc-G0.5 reacted with ethylenediamine (EDA) through amidation to yield Boc-G1. To obtain higher generation of the dendron, MA and EDA were used stepwise. As a result, "half generations" (Boc-G0.5, Boc-G1.5 and Boc-G2.5) and "full generations" (Boc-G1 and Boc-G2) were obtained. ${ }^{1} \mathrm{H}$ NMR spectroscopy confirmed the successful synthesis of half generations (BocG0.5, Boc-G1.5 and Boc-G2.5) (SI). All the ester-terminated half-generations were deprotected with trifluoroacetic acid (TFA) to yield the dendrons with amine group at the focal point $\left(\mathrm{NH}_{2}-\mathrm{G}_{n}, n=0.5,1.5,2.5\right)$. The obtained $\mathrm{NH}_{2}-\mathrm{G}_{n}$ was used without further purification. Compared to other fan-shaped dendrons [42], the synthesis of fan-shaped PAMAM dendrons is facile and the overall yield is high (over 90\%).

Secondly, carboxyl group bearing PBI and SICy were conjugated to the dendrons. As shown in Scheme 2b, through amidation, PBI was attached to the focal point.

The final precise molecular structure of fluorescent dendrimers was characterized by ${ }^{1} \mathrm{H}$ NMR spectra and MALDI-TOF MS (SI). The ${ }^{1} \mathrm{H}$ NMR protonic peaks of Boc-G2.5, PBI-G2.5 and SICy-G2.5 are shown in Fig. 1. The characteristic peaks of both PAMAM dendrons and fluorophore core are observed, indicating the synthesis of desired dendrimers. This strategy has several advantages compared to previously reported methods. Firstly, the 


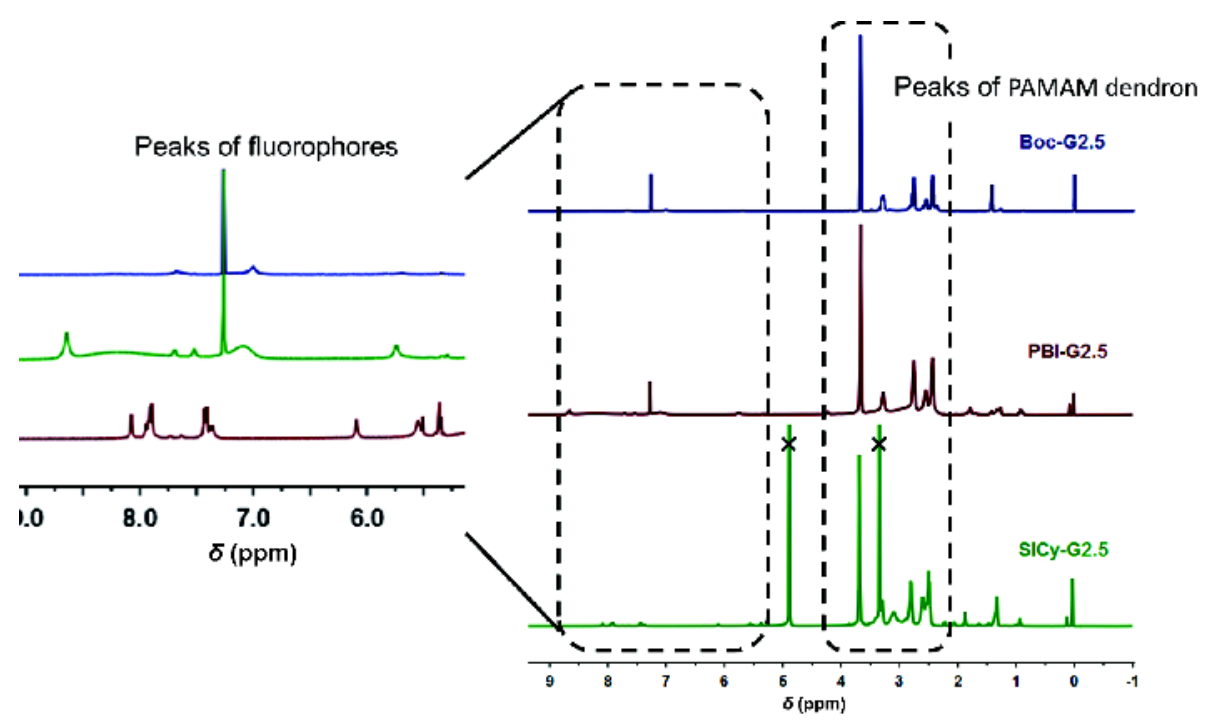

Figure $1{ }^{1} \mathrm{H}$ NMR spectra of Boc-G2.5 (blue), PBI-G2.5 (red) and SICy-G2.5 (green).
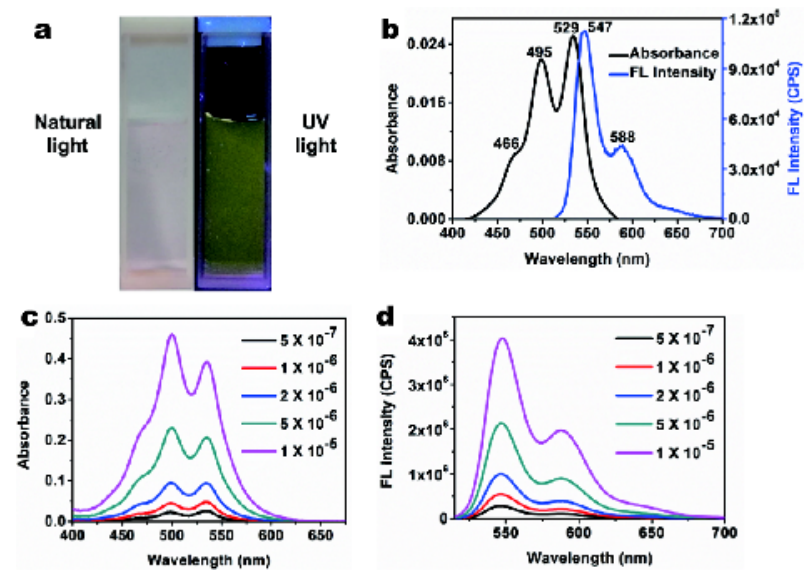

Figure 2 (a) The photographs of aqueous PBI-G2.5 solution under natural (left) and UV light (right). (b) Absorption (dark line) and fluorescent intensity (blue line, excited at $495 \mathrm{~nm}$, slit $1.5 \mathrm{~nm}$ ) of PBIG2.5 $\left(0.5 \mu \mathrm{mol} \mathrm{L}{ }^{-1}\right)$. Concentration-dependent (c) absorption and (d) fluorescence spectra of PBI-G2.5 in water (excited at $495 \mathrm{~nm}$, slit $1.5 \mathrm{~nm})$.

mild amidation reaction can protect peripheral ester from hydrolyzing $[43,44]$. Secondly, directly conjugating the PAMAM dendrons to dyes avoids complicated purification procedures. Thirdly, this method can be applied to a broad range of fluorophores bearing carboxyl groups. In a word, we obtained a series of fluorescent dendrimers with fan-shaped PAMAM modification. Taking PBI dendrimers as example, we further investigated their water solubility, optical, self-assembly and biological performance.
The PBI dendrimers are symmetric dumbbell-shaped [45]. Their molecular geometries were simulated by the Gaussian 09W software (Fig. S3). The steric hindrance of fan-shaped PAMAM dendrons around central PBI can suppress its aggregation and improve the water solubility of dendrimers [46]. Firstly, the water solubility of PBI dendrimer was checked. As shown in Fig. 2a, S4, PBIG2.5 and PBI-G1.5 formed clear red solution in water and emitted yellow green fluorescence under ultraviolet (UV) light. PBI-G2.5 and PBI-G1.5 displayed good watersolubility ( $>10 \mathrm{mg} \mathrm{mL}^{-1}$ and $>7 \mathrm{mg} \mathrm{mL}^{-1}$, respectively), however, PBI-G0.5 was not water-soluble. With increasing dendritic generation, the solubility of PBI dendrimer is enhanced. Then, the optical properties of aqueous PBI dendrimers were investigated. PBI-G2.5 has three main absorption peaks at 466, 495, and $530 \mathrm{~nm}$ in the UV-vis range (Fig. 2b). Fluorescence spectrum of aqueous PBIG2.5 solution shows a maximum emission peak at $542 \mathrm{~nm}$ and a shoulder at $588 \mathrm{~nm}$, which can avoid the interference from biological auto-fluorescence [33]. The concentration-dependent UV-vis absorption (Fig. 2b) and fluorescence (Fig. 2d) properties of aqueous PBI-G2.5 were further investigated. Even at high concentrations, the clear characteristic absorption peaks and strong fluorescence of PBI-G2.5 were observed, indicating its good water solubility [5]. Similar absorption and fluorescence properties for PBI-G1.5 were found (Fig. S5). The fluorescence intensity of PBI-G2.5 is higher than that of PBI-G1.5 at the same concentration due to the decreased aggregation degree of PBI-G2.5 resulting from larger 


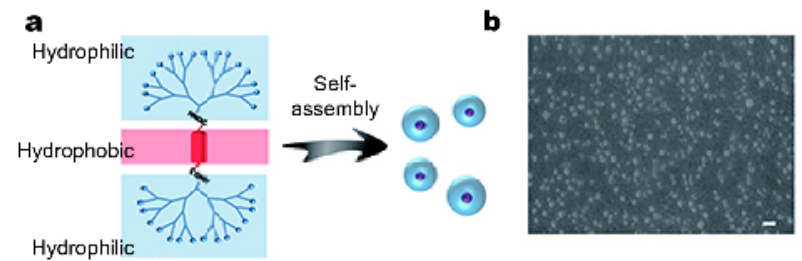

c
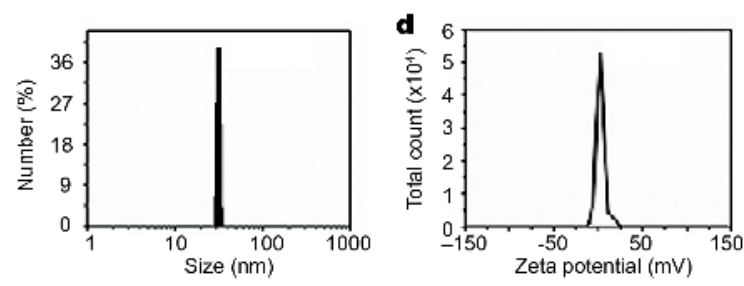

Figure 3 (a) Schematic self-assembly of amphiphilic dendrimer in water. (b) SEM micrographs of PBI-G2.5 nanoparticles $\left(10 \mu \mathrm{mol} \mathrm{L}^{-1}\right)$. Scale bar is $100 \mathrm{~nm}$. (c) DLS data of PBI-G2.5 in deionized water $\left(10 \mu \mathrm{mol} \mathrm{L}{ }^{-1}\right)$. (d) Zeta potential of PBI-G2.5 in deionized water $\left(10 \mu \mathrm{mol} \mathrm{L}^{-1}\right)$.
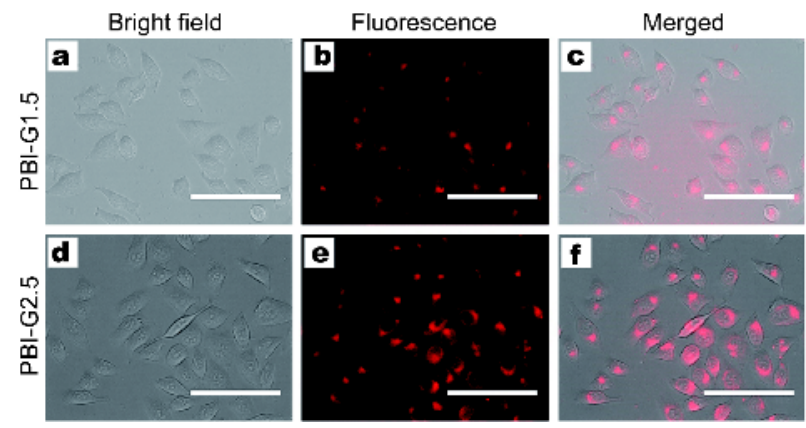

Figure 4 Bright field images of (a) PBI-G1.5, (d) PBI-G2.5; fluorescence images of (b) PBI-G1.5, (e) PBI-G2.5 on the red channel and the overlay images of (c) PBI-G1.5, (f) PBI-G2.5 of HeLa cells incubated with PBIG1.5 and PBI-G2.5 $\left(5 \mu \mathrm{mol} \mathrm{L}^{-1}\right)$ after $2 \mathrm{~h}$. Scale bar is $100 \mu \mathrm{m}$.

steric hindrance of PAMAM dendrons. Therefore, with fan-shaped PAMAM dendron modification, PBI dendrimers possessed good water solubility and strong fluorescence in water, which fulfills the requirement of bioimaging.

Owing to the rigid planar structure of PBI and amphiphilic nature of PBI dendrimers, the dendrimers are likely to self-assemble into nanostructures in water (Fig. 3a) [47]. To give further insight of the morphology, size, and surface charge of PBI dendrimers, SEM, DLS and zeta potential measurements were carried out. The self-assembly of PBI-G2.5 was uniform nanoparticles with the size of $30 \mathrm{~nm}$ (Fig. 3b). The hydrodynamic size of PBIG2.5 nanoparticle was $32 \mathrm{~nm}$ (Fig. 3c), which is larger than the size of hard core measured by SEM due to the formation of PAMAM hydration layer. The zeta potential measurement showed the surface potential of PBI-G2.5
(Fig. 3d) was $2.46 \mathrm{mV}$. This weak positive zeta potential might be caused by the repeated tertiary amine units in the interior of PAMAM dendrimers [48]. In comparison, the self-assembly of PBI-G1.5 exhibited larger size $(91 \mathrm{~nm})$ and lower zeta potential $(0.09 \mathrm{mV})$ (Fig. S6). Generally, it is reported that nanoparticles with smaller size and more positive surface charge can be faster internalized by cell endocytosis [49,50]. Therefore, PBIG2.5 nanoparticles with small size and positive surface charge should have great potential in cell imaging.

To assay the cell uptake and live cell fluorescence imaging performance of PBI dendrimers, HeLa cells were incubated with PBI-G2.5 and PBI-G1.5 solutions $\left(5 \mu \mathrm{mol} \mathrm{L}{ }^{-1}\right)$, respectively. After $2 \mathrm{~h}$ of incubation, strong red fluorescence of PBI-G2.5 was observed (Fig. 4, S7), indicating its effective cellular uptake efficiency. The merging of the bright field and fluorescence images shows that the red fluorescence is located clearly in the cytoplasm of the HeLa cells (Fig. 4c, f). Compared to PBIG2.5, relatively weak fluorescence intensity of PBI-G1.5 was detected (Fig. 4 b, e). These results indicated that PBIG2.5 possesses good ability for live cell fluorescence imaging.

PBI dyes barely undergo photobleaching with long time irradiation of the excitation laser owing to their excellent chemical and optical stability [51]. Therefore, the longterm fluorescence imaging performance of PBI dendrimers were further investigated. We performed realtime monitoring of HeLa cells incubated with PBI-G2.5 and PBI-G1.5 up to $48 \mathrm{~h}$. The fluorescence intensity of PBI dendrimers in HeLa cells at a series of time points (Fig. 5) was recorded. With the incubation duration from 0.3 to $48 \mathrm{~h}$, their fluorescence intensity increased steadily, indicating the continuous accumulation of PBI dendrimers without obvious excretion. In accordance with our previous results, PBI-G2.5 showed stronger fluorescence than PBI-G1.5 during the incubation. Overall, these results suggested that $\mathrm{PBI}$ based fluorescent dendrimers achieved long-term imaging of live cells.

As good cytocompatibility is essential for bioimaging agents $[1,5]$, the cytotoxicity of fluorescent dendrimers was evaluated on HeLa cell line using CCK-8 assays. The HeLa cells were treated with PBI dendrimers at different concentrations. After $24 \mathrm{~h}$ of incubation, the cell viabilities of these dyes were tested (Fig. 6). The cytocompatibility of fluorescent dendrimers was concentration-dependent. The cell viability of PBI-G2.5 is above $80 \%$ at all the tested concentrations, suggesting the good biocompatibility of PBI-G2.5 (under $25 \mu \mathrm{mol} \mathrm{L}{ }^{-1}$ ). Besides, with increasing generation, the fluorescent den- 


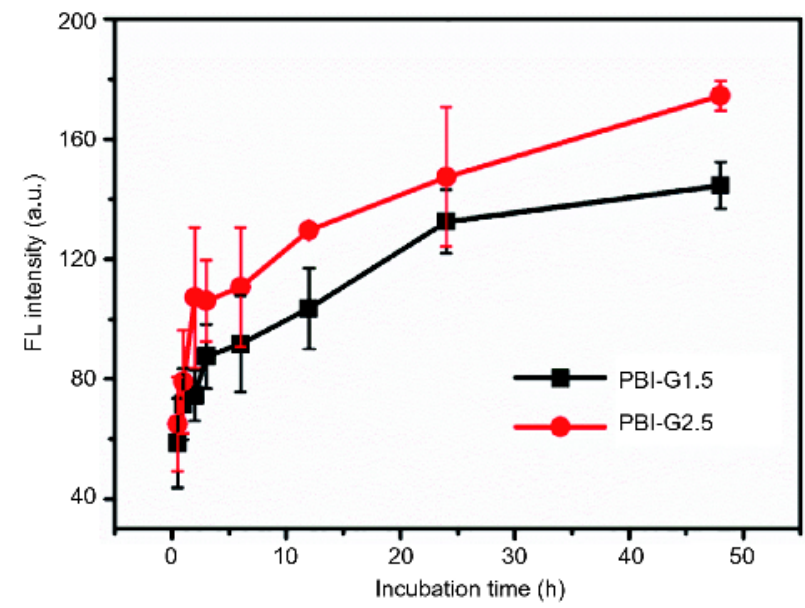

Figure 5 Dynamic fluorescence intensity of PBI dendrimers incubated with HeLa cells at different time points $\left(E_{\mathrm{x}}=495 \mathrm{~nm}, E_{\mathrm{m}}=547 \mathrm{~nm}\right)$.

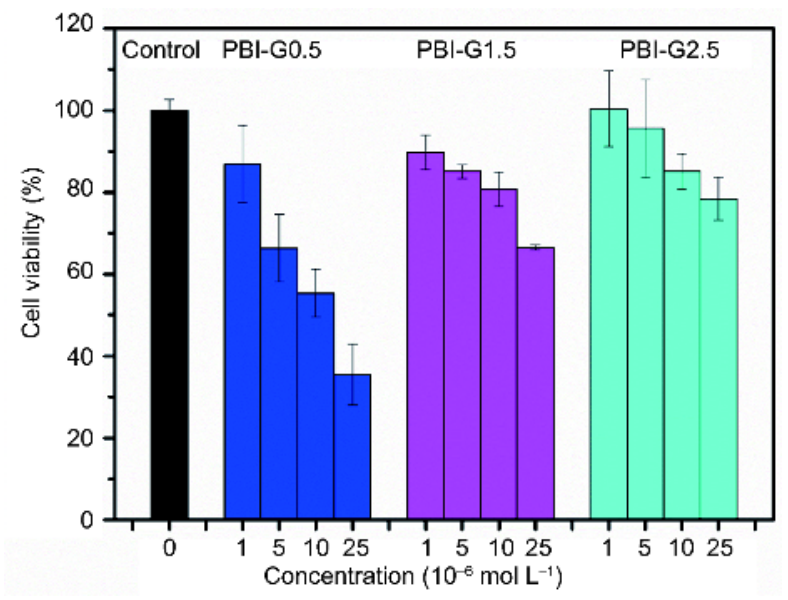

Figure 6 Cell viability of Hela cells incubated with different concentrations $\left(1,5,10,25 \mu \mathrm{mol} \mathrm{L}^{-1}\right)$ of various generations of PBI (PBIG0.5, PBI-G1.5, PBI-G2.5).

drimers showed less toxicity. It is speculated that higher generation dendrimers with higher water solubility and smaller size performed better cytocompatibility.

Additionally, the water solubility, optical properties and cytocompatibility of SICy dendrimers were checked and showed similar results (Fig. S8, S9). With fluorescence emission in red region, SICy-G2.5 also achieved live cell fluorescence imaging (Fig. S10). These data further proved that our strategy is effective for modifying fluorescent dyes.

\section{CONCLUSIONS}

In conclusion, we present an effective strategy to prepare water-soluble fluorescent dendrimers for live cell ima- ging. With modification of fan-shaped PAMAM dendrons, a series of PBI and SICy cored dendrimers were obtained. With increasing generations, the dendrimers possess better water solubility, fluorescent properties and cytocompatibility. Moreover, the PBI dendrimers can self-assemble into nanoparticles, which showed rapid cellular uptake efficiency by endocytosis. Owing to the excellent physical stability and cytocompatibility, PBI dendrimers achieved long-term imaging of live cells. Our study provides a simple but effective method for organic fluorophores modification, which has potential for constructing theranostic platforms in combination of functional dendrimers and fluorescent dyes.

\section{Received 9 February 2018; accepted 6 March 2018;} published online 21 March 2018

1 Chen M, Yin M. Design and development of fluorescent nanostructures for bioimaging. Prog Polymer Sci, 2014, 39: 365-395

2 Liu K, Xu Z, Yin M, et al. A multifunctional perylenediimide derivative (DTPDI) can be used as a recyclable specific $\mathrm{Hg}^{2+}$ ion sensor and an efficient DNA delivery carrier. J Mater Chem B, 2014, 2: 2093-2096

3 Liu K, $\mathrm{Hu} \mathrm{Y,} \mathrm{Xu} \mathrm{Z,} \mathrm{et} \mathrm{al.} \mathrm{Fluorescent} \mathrm{sensor} \mathrm{for} \mathrm{rapid} \mathrm{detection} \mathrm{of}$ nucleophile and convenient comparison of nucleophilicity. Anal Chem, 2017, 89: 5131-5137

4 Yao Q, Lü B, Ji C, et al. Supramolecular host-guest system as ratiometric $\mathrm{Fe}^{3+}$ ion sensor based on water-soluble pillar[5]arene. ACS Appl Mater Interfaces, 2017, 9: 36320-36326

5 Sun M, Müllen K, Yin M. Water-soluble perylenediimides: design concepts and biological applications. Chem Soc Rev, 2016, 45: $1513-1528$

6 Liu K, Xu Z, Yin M. Perylenediimide-cored dendrimers and their bioimaging and gene delivery applications. Prog Polymer Sci, 2015, 46: $25-54$

7 Dong R, Zhou Y, Zhu X. Supramolecular dendritic polymers: from synthesis to applications. Acc Chem Res, 2014, 47: 2006-2016

8 Albertazzi L, Storti B, Marchetti L, et al. Delivery and subcellular targeting of dendrimer-based fluorescent $\mathrm{pH}$ sensors in living cells. J Am Chem Soc, 2010, 132: 18158-18167

9 Han HJ, Kannan RM, Wang S, et al. Multifunctional dendrimertemplated antibody presentation on biosensor surfaces for improved biomarker detection. Adv Funct Mater, 2010, 20: 409-421

10 Li HJ, Du JZ, Du XJ, et al. Stimuli-responsive clustered nanoparticles for improved tumor penetration and therapeutic efficacy. Proc Natl Acad Sci USA, 2016, 113: 4164-4169

11 Chen S, Fan JX, Qiu WX, et al. Self-assembly drug delivery system based on programmable dendritic peptide applied in multidrug resistance tumor therapy. Macromol Rapid Commun, 2017, 38 : 1700490

12 Wei T, Chen C, Liu J, et al. Anticancer drug nanomicelles formed by self-assembling amphiphilic dendrimer to combat cancer drug resistance. Proc Natl Acad Sci USA, 2015, 112: 2978-2983

13 Sun M, Yin W, Dong X, et al. Fluorescent supramolecular micelles for imaging-guided cancer therapy. Nanoscale, 2016, 8: 5302-5312

14 Cheng W, Cheng $\mathrm{H}$, Wan S, et al. Dual-stimulus-responsive fluorescent supramolecular prodrug for antitumor drug delivery. 
Chem Mater, 2017, 29: 4218-4226

15 Zhang S, Guo W, Wei J, et al. Terrylenediimide-based intrinsic theranostic nanomedicines with high photothermal conversion efficiency for photoacoustic imaging-guided cancer therapy. ACS Nano, 2017, 11: 3797-3805

16 Shao S, Zhou Q, Si J, et al. A non-cytotoxic dendrimer with innate and potent anticancer and anti-metastatic activities. Nat Biomed Eng, 2017, 1: 745-757

$17 \mathrm{Xu} \mathrm{Z}, \mathrm{He} \mathrm{B}$, Shen J, et al. Fluorescent water-soluble perylenediimide-cored cationic dendrimers: synthesis, optical properties, and cell uptake. Chem Commun, 2013, 49: 3646

$18 \mathrm{Xu} \mathrm{Z}$, He B, Wei W, et al. Highly water-soluble perylenediimidecored poly(amido amine) vector for efficient gene transfection. J Mater Chem B, 2014, 2: 3079-3086

19 Shen D, Zhou F, Xu Z, et al. Systemically interfering with immune response by a fluorescent cationic dendrimer delivered gene suppression. J Mater Chem B, 2014, 2: 4653-4659

20 Jiang L, Ding L, He B, et al. Systemic gene silencing in plants triggered by fluorescent nanoparticle-delivered double-stranded RNA. Nanoscale, 2014, 6: 9965-9969

21 Wei P, Chen J, Hu Y, et al. Dendrimer-stabilized gold nanostars as a multifunctional theranostic nanoplatform for CT imaging, photothermal therapy, and gene silencing of tumors. Adv Healthcare Mater, 2016, 5: 3203-3213

22 Zhang S, Li J, Wei J, et al. Perylenediimide chromophore as an efficient photothermal agent for cancer therapy. Sci Bull, 2018, 63: 101-107

23 Qiao Z, Shi X. Dendrimer-based molecular imaging contrast agents. Prog Polymer Sci, 2015, 44: 1-27

24 Astruc D, Boisselier E, Ornelas C. Dendrimers designed for functions: from physical, photophysical, and supramolecular properties to applications in sensing, catalysis, molecular electronics, photonics, and nanomedicine. Chem Rev, 2010, 110: 18571959

25 Lamy CM, Sallin O, Loussert C, et al. Sodium sensing in neurons with a dendrimer-based nanoprobe. ACS Nano, 2012, 6: 11761187

26 Srikun D, Albers AE, Chang CJ. A dendrimer-based platform for simultaneous dual fluorescence imaging of hydrogen peroxide and $\mathrm{pH}$ gradients produced in living cells. Chem Sci, 2011, 2: 1156

27 Dougherty CA, Vaidyanathan S, Orr BG, et al. Fluorophore: dendrimer ratio impacts cellular uptake and intracellular fluorescence lifetime. Bioconjugate Chem, 2015, 26: 304-315

28 Ravizzini G, Turkbey B, Barrett T, et al. Nanoparticles in sentinel lymph node mapping. WIREs-Nanmed Nanobiotechnol, 2009, 1: 610-623

29 Caminade AM, Hameau Ã̃, Majoral JP. Multicharged and/or water-soluble fluorescent dendrimers: properties and uses. Chem Eur J, 2009, 15: 9270-9285

30 Georgiev NI, Sakr AR, Bojinov VB. Design and synthesis of novel fluorescence sensing perylene diimides based on photoinduced electron transfer. Dyes Pigments, 2011, 91: 332-339

31 Wang B, Luo Y, Jia X, et al. Synthesis and characterization of fanshape PAMAM dendrons. Acta Polymerica Sinica, 2004: 304-308

32 Dean KM, Palmer AE. Advances in fluorescence labeling strategies for dynamic cellular imaging. Nat Chem Biol, 2014, 10: 512-523

33 Yin M, Shen J, Pflugfelder GO, et al. A fluorescent core-shell dendritic macromolecule specifically stains the extracellular matrix. J Am Chem Soc, 2008, 130: 7806-7807

34 Yin M, Kuhlmann CRW, Sorokina K, et al. Novel fluorescent core- shell nanocontainers for cell membrane transport. Biomacromolecules, 2008, 9: 1381-1389

35 Wang W, Li Y, Cheng L, et al. Water-soluble and phosphoruscontaining carbon dots with strong green fluorescence for cell labeling. J Mater Chem B, 2014, 2: 46-48

36 Li J, Guo K, Shen J, et al. A difunctional squarylium indocyanine dye distinguishes dead cells through diverse staining of the cell nuclei/membranes. Small, 2014, 10: 1351-1360

$37 \mathrm{Xu} \mathrm{Z,} \mathrm{Guo} \mathrm{K,} \mathrm{Yu} \mathrm{J,} \mathrm{et} \mathrm{al.} \mathrm{A} \mathrm{unique} \mathrm{perylene-based} \mathrm{DNA} \mathrm{inter-}$ calator: localization in cell nuclei and inhibition of cancer cells and tumors. Small, 2014, 116: 4087-4092

38 Ji C, Zheng Y, Li J, et al. An amphiphilic squarylium indocyanine dye for long-term tracking of lysosomes. J Mater Chem B, 2015, 3: 7494-7498

39 Xu Z, Cheng W, Guo K, et al. Molecular size, shape, and electric charges: essential for perylene bisimide-based DNA Intercalator to localize in cell nuclei and inhibit cancer cell growth. ACS Appl Mater Interfaces, 2015, 7: 9784-9791

40 Ye Y, Zheng Y, Ji C, et al. Self-assembly and disassembly of amphiphilic zwitterionic perylenediimide vesicles for cell membrane imaging. ACS Appl Mater Interfaces, 2017, 9: 4534-4539

41 Esfand R, Tomalia DA. Laboratory synthesis of poly (amidoamine) (PAMAM) dendrimers. Dendrimers and other dendritic polymers, 2001: 587-604

42 Haag R, Sunder A, Stumbé JF. An approach to glycerol dendrimers and pseudo-dendritic polyglycerols. J Am Chem Soc, 2000, 122: 2954-2955

43 Kaiser H, Lindner J, Langhals H. Synthese von nichtsymmetrisch substituierten Perylen-Fluoreszenzfarbstoffen. Chem Ber, 1991, 124: 529-535

44 Schmidt CD, Böttcher C, Hirsch A. Synthesis and aggregation properties of water-soluble newkome-dendronized perylenetetracarboxdiimides. Eur J Org Chem, 2007, 2007: 5497-5505

45 Zhang X, Chen Z, Würthner F. Morphology control of fluorescent nanoaggregates by co-self-assembly of wedge- and dumbbellshaped amphiphilic perylene bisimides. J Am Chem Soc, 2007, 129: 4886-4887

46 Yang SK, Shi X, Park S, et al. Monovalent, clickable, uncharged, water-soluble perylenediimide-cored dendrimers for target-specific fluorescent biolabeling. J Am Chem Soc, 2011, 133: 9964-9967

47 Zhang X, Rehm S, Safont-Sempere MM, et al. Vesicular perylene dye nanocapsules as supramolecular fluorescent $\mathrm{pH}$ sensor systems. Nat Chem, 2009, 1: 623-629

48 Choi JS, Nam K, Park JY, et al. Enhanced transfection efficiency of PAMAM dendrimer by surface modification with 1-arginine. J Control Release, 2004, 99: 445-456

49 Liu X, Xiang J, Zhu D, et al. Fusogenic reactive oxygen species triggered charge-reversal vector for effective gene delivery. Adv Mater, 2016, 28: 1743-1752

$50 \mathrm{Hu} \mathrm{X}, \mathrm{Hu}$ J, Tian J, et al. Polyprodrug amphiphiles: hierarchical assemblies for shape-regulated cellular internalization, trafficking, and drug delivery. J Am Chem Soc, 2013, 135: 17617-17629

51 Würthner F, Saha-Möller CR, Fimmel B, et al. Perylene bisimide dye assemblies as archetype functional supramolecular materials. Chem Rev, 2016, 116: 962-1052

Acknowledgements This work was financially supported by the National Natural Science Foundation of China (21774007, 21574009 and 51521062), and the Higher Education and High-quality and World-class Universities (PY201605). 
Author contributions Yin M and Su Z initiated and guided the work. All authors contributed to the discussion and preparation of the manuscript. The final version of the manuscript was approved by all authors.
Conflict of interest The authors declare no conflict of interest.

Supplementary information Experimental details and supporting data are available in the online version of the paper

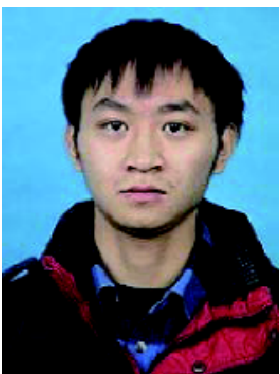

Yang Cai received his Bachelor's degree from Beijing University of Chemical Technology in 2015. He is now a $\mathrm{PhD}$ candidate under the supervision of Prof. Meizhen Yin. His research interest focuses on the synthesis and bio-application of fluorescent dyes.

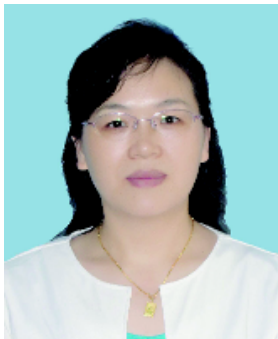

Meizhen Yin got her PhD in Organic Chemistry from Dresden University of Technology, Germany in 2004. Afterwards, she worked as a postdoctor in Prof. Klaus Müllen group in Max Planck Institute for Polymer Research Mainz, Germany. Since 2009, she is a professor at Beijing University of Chemical Technology. Currently, she focuses on the design and synthesis of functional fluorescent macromolecules, multifunctional organic/inorganic nanoparticles and their biological applications.

\section{基于扇形PAMAM树枝制备的水溶性菼光树枝状分子及其长效活细胞苂光成像}

蔡阳, 冀辰东, 张少博, 苏志强, 尹梅贞 ${ }^{*}$

摘要 亲水聚酰胺-胺型(PAMAM)树枝状分子能够提高苂光染料水溶性和生物相容性，被广泛应用于生物苂光成像、药物、基因递送等 领域. 本文报道了一系列以扇形PAMAM为树枝, 以荧光染料为核的水溶性苂光树枝状分子. 扇形PAMAM树枝可通过酰胺化反应与羧基 化的菲酰亚胺(PBI)和吲哚方酸菁(SICy)染料相连. 随后, 我们进一步研究了PBI系列树枝状分子的物理性质及生物性能. PBI-G2.5具有良 好的水溶性, 强荧光发射, 并能在水中自组装形成 $30 \mathrm{~nm}$ 的纳米粒子. 细胞实验表明, PBI-G2.5被细胞摄取后在细胞质富集, 且48 小时后仍 可检测到强的荧光. 因此, 本合成方法可以有效制备水溶性、生物相容性良好的苂光树枝状分子, 并在长效活细胞荧光成像中有应用前景. 